\title{
Leadership Development in Health Care: The Role of Clinical Leaders
}

\author{
Kyriakidou Niki', Goula Aspasia ${ }^{2 *}$, Pierrakos George ${ }^{3}$, Sepetis Anastasios ${ }^{4}$, Adamou Marios ${ }^{5}$ \\ ${ }^{1}$ Leeds Beckett University, Leeds, UK \\ ${ }^{2}$ Professor Associate, Master of Health and Social Care Management, University of West Attica, Egaleo, Greece \\ ${ }^{3}$ Professor, Master of Health and Social Care Management, University of West Attica, Egaleo, Greece \\ ${ }^{4}$ Professor Assistant, Master of Health and Social Care Management, University of West Attica, Egaleo, Greece \\ ${ }^{5}$ Professor and Consultant Psychiatrist in Neurodevelopmental Psychiatry (ADHD and ASD) at South West Yorkshire Partnership \\ NHS Foundation Trust, Wakefield, UK \\ Email: *agoula@uniwa.gr
}

How to cite this paper: Niki, K., Aspasia, G., George, P., Anastasios, S., \& Marios, A. (2021). Leadership Development in Health Care: The Role of Clinical Leaders. Journal of Human Resource and Sustainability Studies, 9, 231-249.

https://doi.org/10.4236/jhrss.2021.92015

Received: February 26, 2021

Accepted: May 4, 2021

Published: May 7, 2021

Copyright $\odot 2021$ by author(s) and Scientific Research Publishing Inc. This work is licensed under the Creative Commons Attribution International License (CC BY 4.0).

http://creativecommons.org/licenses/by/4.0/

(c) (i) Open Access

\begin{abstract}
Aim: This paper presents evidence on the impact of leadership development programmes on developing key competencies of clinical leaders in the European Health Sector. Methods: An International Leadership Development Programme has been used as a pilot to assess effectiveness on skills development and leadership styles. A longitudinal pre and post-test design was used, with a sample of clinical professionals attending the programme within three years. A control group provided a method of isolating the impact of the programme. Results: We found that participation in health leadership programmes has a positive impact on health professionals' leadership potential; leadership styles and talent management. However, leadership qualities are also influenced by other factors such as national and organisational culture, structure and team dynamics. Conclusion: The European cases presented in this paper reveal that the higher the contribution of clinicians in management roles, governance, and administration is, the more efficient and productive their healthcare systems become.
\end{abstract}

\section{Keywords}

Clinical Leadership, European Leadership Programmes, Emotional Intelligence, Leadership Development, Clinical Competencies, Talent Management

\section{Introduction}

The landscape of the European Healthcare Sector is undergoing significant 
transformation (Veronesi et al., 2018; Kyriakidou \& Papagiannopoulos, 2018; Kyriakidou et al., 2017; Veronesi et al., 2013; Enock \& Markwell, 2010; Hamilton et al., 2008) with the considerable complexity leading to an intense focus on the effectiveness of leadership at different levels (Auerbach et al., 2018). Effective leadership is enhancing local organisational cultures to deliver high standards of compassionate and safe healthcare services. Leadership is one of the critical determinants in shaping organisational culture, and along with some other key performance indicators, it is, therefore, fundamental to ensure the development of the leadership behaviours, strategies and qualities of healthcare professionals (Veronesi et al., 2018; Kyriakidou \& Papagiannopoulos, 2018; Kyriakidou et al., 2017; The King's Fund, 2011). Worldwide, the majority of systems consider the hybrid role of clinician-manager (such as Clinical Director) essential for healthcare effectiveness, overall organisational performance (Kyriakidou and Papagiannopoulos, 2018; Veronesi et al., 2018; Kirkpatrick et al., 2016) as well as for a range of other positive outcomes relating to local communities, healthcare users and other stakeholders (Kirkpatrick et al., 2016; Mountford and Webb, 2009).

The project focuses on the health sector need for clinical leaders and the development of the European Programmes for Healthcare Leadership and Development. The key to this aim is to identify and meet critical personal and system needs with skills and competencies, supporting health leaders across Europe. For that purpose, this study critically evaluates the effectiveness of one international health leadership programme delivered in a group of Clinical international leaders. The programme was delivered in the U.K. All surgeons who participated in the international leadership programme during 2015-2019 were included. The study was conducted in two phases. In Phase I, one of the researchers conducted individual in-depth face-to-face and telephonic audio-recorded interviews with sixteen thoracic surgeons. The Second Phase of the research study was focused on developing case studies derived from two in-depth interviews with two senior consultants and senior executive members of the European Society of Thoracic Surgeon. The data produced is based on their cross-national experience in different health settings.

\section{Exploring the Need for Clinical Leadership Development}

The health care sector operates in a context influenced by political, economic, social and environmental factors (Kyriakidou \& Papagiannopoulos, 2018). In such an environment, with several forces affecting sector leadership (Figure 1) accompanied by constant reforms, the type of leadership required cannot be constant. While the basics of management skills remain (i.e. managing people, operations, budgets), other qualities peculiar to healthcare leaders also manifest. As Figure 1 demonstrates, the sector has financial and human resource constraints and relies on efficient leadership to ensure an appropriate and efficacious strategy to utilise the limited resources available. Health sector leaders are committed to delivering to the patients, communities, and societies for which they have a responsibility and 


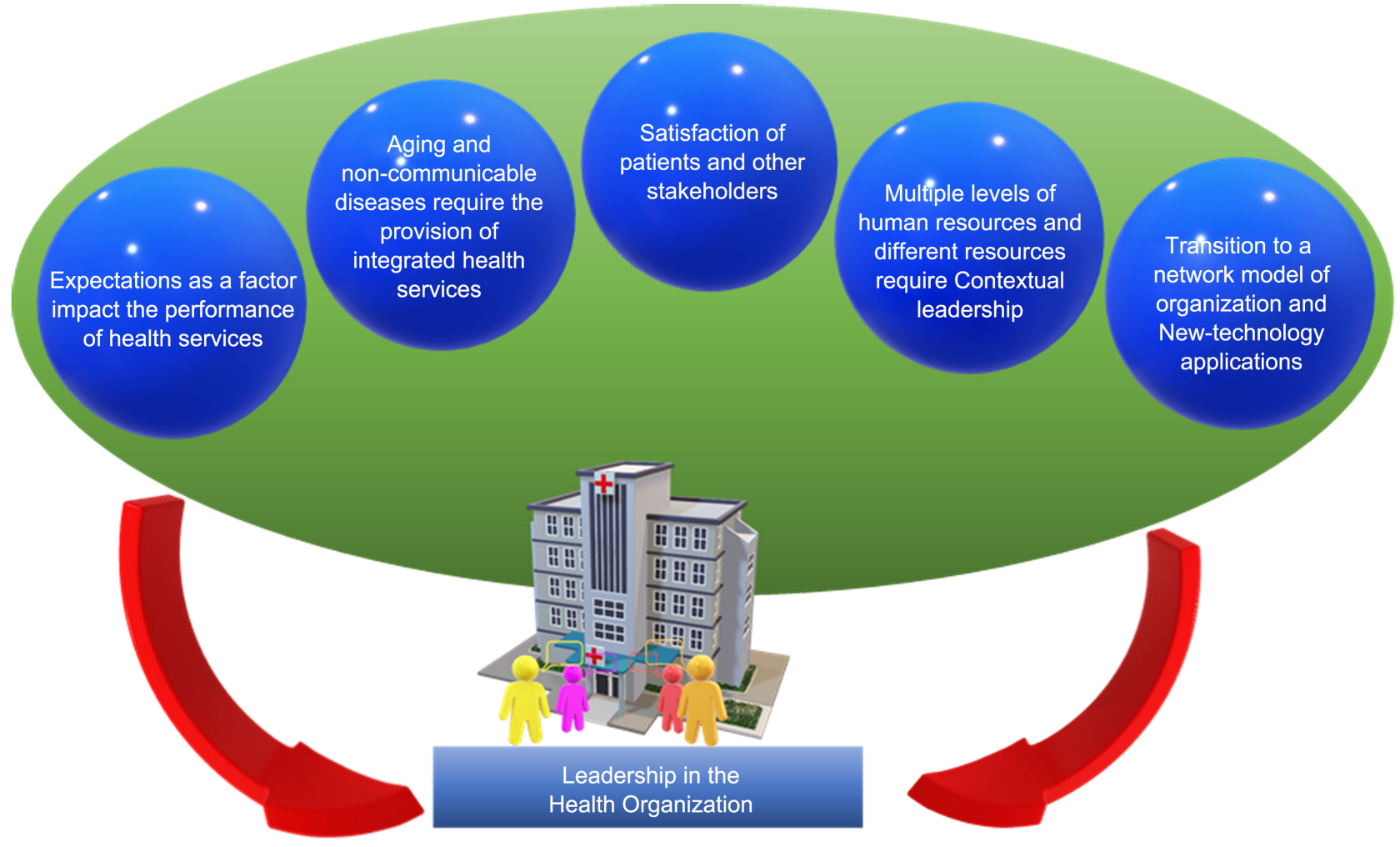

Figure 1. Five forces impact health sector leadership (Authors' development and elaboration).

to the workforce in their organizations as well as to meet the expectations of "governance" stakeholders, including shareholders in private sector health organisations or government agencies in public sector ones (Turner, 2020, pp: 1-16). To satisfy such a diverse and wide-ranging group will require those in leadership roles to match up to stringent requirements in terms of capability and credibility and deliver excellence and transformation (including digital transformation) at times of volatility, uncertainty, complexity, and ambiguity.

One of these is the knowledge of the healthcare system of the country for which they work. In the U.K., the involvement of Clinical leaders in Clinical Commissioning Groups and other executive roles has been echoed in health leadership literature, commissions and government reports (Francis, 2013). Recent NHS leadership reports, commissions, and other government publications have considered clinician leadership development and engagement of paramount importance to improving patients' quality and safety (MacPhee et al., 2013; Mountford and Webb, 2009). For example, recent Patient Public Involvement (PPI) reports published on Quality of Healthcare suggest critical improvements in healthcare services and quality can be effectively achieved by actively involved more consultants and patients in the reform process (Crocker et al., 2018; Daly et al., 2014).

Still, the role of the clinical leaders remains quite unclear and complex relevant research conducted in this studied area demonstrated that the involvement of health consultants as board members, Chief Executive Officers and other se- 
nior positions in hospitals varies in different countries (Veronesi et al., 2018; Kyriakidou \& Papagiannopoulos, 2018; Dorgan et al., 2010).

Reflecting on an increasing interest of health policymakers and practitioners in engaging clinicians in governance and management of health care organisations (The King's Fund, 2012; Ham and Dickinson, 2008), Veronesi et al. (2018) argue that increased participation of clinician in strategic decision-making levels is likely to achieve for positive outcomes for the healthcare organisations. Similarly, research from Clay-Williams et al. (2014) shows the importance of engaging more clinicians in management and Clinical Commissioning Group roles as clinical leaders are capable professionals with on the job experience in managing the departmental structure and work process, patients outcomes, safety and quality issues as well as the capability for intelligent and informed actions in regards to healthcare quality provision and organisational processes.

Also, effective leadership from clinical professionals can make a difference in how organisations in the health sector operate and how they provide healthcare services. For example, Healthcare Leaders could

- have a significant impact on organisational performance and culture (Gauld, 2017; Reichenpfader et al., 2015).

- Provide high standards of quality, safety, and patients oriented health care environment by implementing clear objectives among departmental teams, increased participation at all levels in an organisational hierarchy, continuous commitment to excellence, and innovation.

- have "positive outcomes across a range of patient-oriented, staff-oriented or organisational measures including patient care quality and patient satisfaction; employee satisfaction and organisational commitment; on organisational productivity and team working and on interprofessional collaboration" (Jayaraman et al., 2018).

- promote a mission and vision for compassionate and quality care amongst healthcare personnel, which in turn communicated and further implemented at all levels of front line health professionals (West et al., 2014).

\section{Effectiveness of Leadership Development Programmes}

Even though critical research studies (Hodzic et al., 2018; Nelis et al., 2009; Groves et al., 2008) have demonstrated the effectiveness of different approaches in enhancing leaders' cognitive and emotional competencies within different sectors, the existing leadership programmes lack a reliable academic model or framework of skills, applicable to each sector needs such as Healthcare Sector. There is a limited amount of studies that measure the design of those training types, and usually without considering key information on training procedures. More specifically, the dismissal of training conception, its duration, and the activities carried out have negatively impacted the validity of the process (Groves et al., 2008). In their meta-analysis investigation, Hodzic et al. (2018) conclude that leadership development programs based on ability models (Mayer et al., 2002) are more likely to develop and possess higher outcomes to improve emo- 
tion traits than miscellaneous models. However, the acknowledged power of the development depends on the duration and the circumstances of those interventions.

The complexity to identify and apply the appropriate training type based on the needs and focus on the development plan that clinical leaders need to fulfil in a specific timeframe as set by their Personal Development Plan (PDP), considers being one of the critical problems identified at this stage (i.e. development for consultancy level roles) (Pierrakos et al., 2006). While the success of using leadership and development training programmes for health professionals has been one of the critical issues raised by many scholars, Cherniss \& Goleman (2001) suggest that different interpersonal skills and competencies could be improved. To achieve that, they suggest that training providers should consider the differences between emotional and cognitive learning during their design and implementation of such programmes. Cognitive learning refers to the process where new knowledge added to neural circuitry. In contrast, emotional learning is a more sophisticated practice where changing personal and social behaviours (i.e., empathising, listening to better, controlling anger) and habits already learnt is also required (Perez-Lopez, 2019). In other words, "developing emotional intelligence requires to unlearn old habits of thought, feeling, and action that are deeply ingrained, and grow new ones" (Cherniss and Goleman, 2001). Reflecting on that, Cherniss et al. (1998) argued that in order to achieve effective managerial performance, a health leader should develop the ability to use both emotional and cognitive competencies together in his daily professional practice. There is an increasing interest in the development of Emotional Intelligence qualities in healthcare field jobs. More specifically, there is an increasing focus on patient-centred health provision and demands (Pierrakos et al., 2017), which requires not only delivering quality healthcare but also developing effective long term relationships and interactions (Pierrakos et al., 2016) with patients and other key stakeholders, which in return influences organisational effectiveness and performance (Warren, 2013). In light of the above, emotional intelligence is considered one of the key qualities to doctors' professional competence framework, essential to their communication skills, and critical for patient-centred care (Cherry et al., 2014).

Emotional intelligence (E.I.) is the capacity to recognise our own and other people's feelings, motivate ourselves, and manage emotions effectively our emotions and others and us (Gardiner, 1983; Salovey and Mayer, 1990). There is evidence that work professionals with a high level of Emotional Intelligence are effective team-players, be able to cope better with emotional responses work stress and maintain higher job satisfaction (Kafetsios and Zampetakis, 2008). Doctors are expected to be caring, helpful, affectionate, have an unprejudiced empathetic approach, sufficient self-control, and maintain meaningful relations with their colleagues. Higher Emotional Intelligence in doctors plays a significant role in strengthening the doctor-patient relationship related to better patients' quality services, satisfaction, and post-care outcomes (Weng, 2008; Payne, 1985). 


\section{Clinical Leadership Competency Framework (MLCF/CLCF)}

This programme has used as the theoretical framework the Medical/Clinical Leadership Competency Framework (MLCF/CLCF), which has developed initially by the Academy of Medical Royal Colleges (AoMRC) and the NHS Institute for Innovation and Improvement (NHSII), in conjunction with the medical profession and NHS stakeholders (Royal College of Physicians, 2005). Later, the NHS Leadership Academy adopted it to develop doctors' understanding of their role in managing and leading health services.

The ILHP has adopted the MLCF/CLCF to address clinicians' knowledge and critical competencies to be effective in their roles. The framework has been developed to ensure that leadership competencies will be incorporated into education and training for all clinical professions.

There are five domains in the MLCF/CLCF-Demonstrating Personal Qualities, Working with Others, Managing Services, Improving Services and Setting Direction. Reflecting on the leadership competencies outlined in the MLCF/CLCF, it seeks to support clinicians develop the knowledge, skills, attitudes and behaviours required to be effective and emotionally intelligent team players; support others through their leadership roles, and make influential contributions as appropriate. Subsequently, the framework was adopted as the "Leadership Framework" for all health professionals working at NHS, within content for the primary five domains but with two additional domains as suggested by the NHS Leadership Academy for those working at senior levels in organisations (NHS Institute for Innovation and Improvement and Academy of Medical Royal Colleges, 2010). Therefore, it is fair to say that the CLCF supports clinicians in developing the leadership competencies that they will require in practice in their current work and at later stages in their careers as shown in Figure 2.

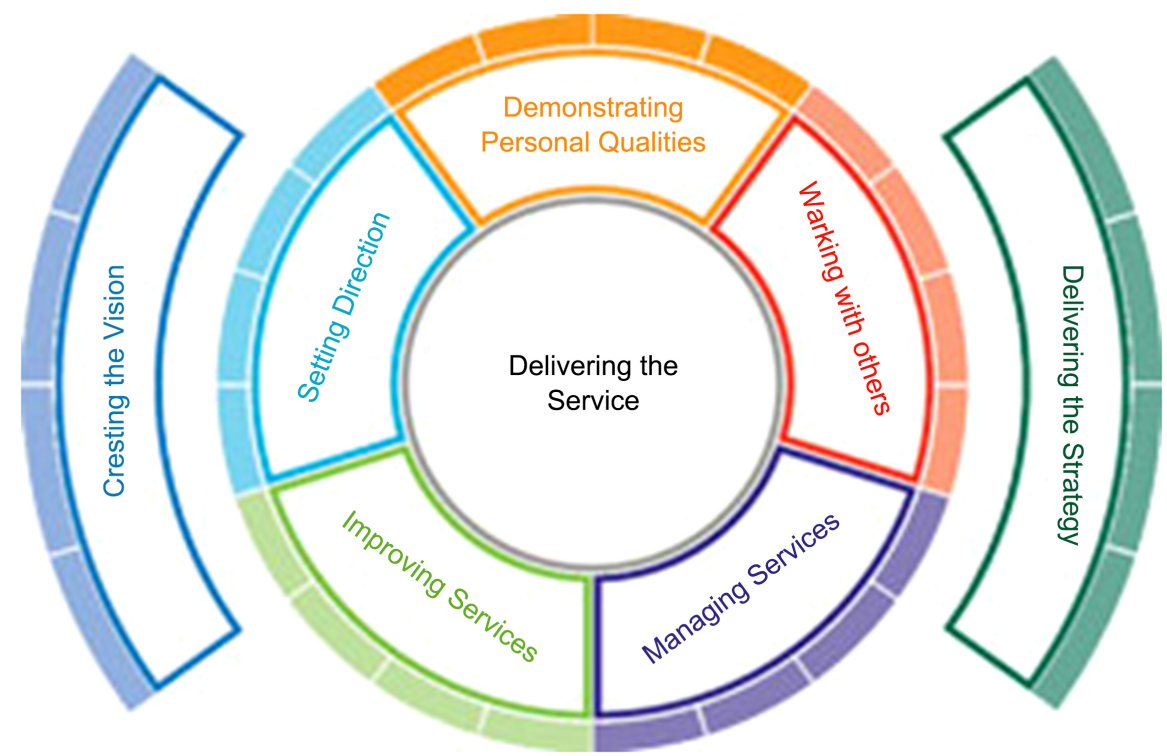

Figure 2. Clinical leadership competency framework. 
All programme materials, action learning, and coursework requirements support developing leadership in clinical settings and the knowledge base outlined in the following illustration of the Clinical Leadership Framework. Using this framework to develop the programme aims and objectives seeks to establish a stronger foundation for developing leadership capability across health care and delivering the changes needed to meet future challenges, and also to develop the leadership competencies required by the Clinicians to become more actively involved in the planning, delivery and transformation of health services.

\section{Purpose of the Working Paper}

This paper seeks to explore the essential competencies of the clinical leaders in the European Healthcare Sector and how they may contribute successfully towards the effective execution of their role responsibilities and organisational effectiveness. The international programme on Clinical Leadership for Thoracic surgeons, under consideration from this study, funded by the European Society of Thoracic Surgeons, demonstrated some key competencies that clinical leaders should possess to be useful in their medical practice leading their staff and promote change within their health organizations. The principal aim is to introduce and critically discuss:

- Leadership development and change management.

- Talent management in health leadership development.

- The relation between Emotional Intelligence and its contribution to health professionals development and leadership (Kyriakidou et al., 2019).

The project follows the successful process in which Goleman and Cherniss (1998) based their research. It consists of 3 days of onsite delivery sessions delivered by professional and academic experts from Leeds Beckett University and the University of West Attica, who taught Thoracic Surgeons across Europe in a pre and post-programme. This course aimed to build knowledge of leadership and management in hospitals (Kyriakidou et al., 2019). In light of this, an understanding of principles and practicalities to manage different contextual situations provided. The designed sessions supplied a framework to success by equipping Thoracic Surgeons with the essential tools, competences and knowledge in order to be able to manage others in an emotionally intelligent way (Perez-Lopez, 2019).

The programme's objective was to advance the understanding of vital leadership and management competencies through action-based learning. Also, participants could use other styles where appropriate: affiliative, coaching, commanding, democratic, pacesetting, visionary (Goleman, 2000) based on their professional background, national and organisational culture influences and organisational structure and infrastructure. Self-awareness and people management skills are also explored and assessed through psychometric tests and action learning activities. A considerable part of the programme focused on understanding business innovation and changed through action learning activities and 
PDP action plans. The programme activities and taught lectures to enable the individuals to assess current work challenges, conducting a PESTLE and SWOT analysis to evaluate health sector issues and develop strategies for coping with challenges and change, and how to influence and persuade their stakeholders (patients, doctors, nurses, health management staff and many others).

\section{Programme Methodology}

The first session of the programme was an introduction to the programme content and structure, where clinical leaders had an opportunity to discuss leading issues that need to address. These issues are related to examining the concept of leadership in the health sector, business change and innovation, decision making and self-awareness and people management using emotional intelligence in their day to day practice.

The second session was divided into two components. Primarily it was based on business processes where participants acknowledge leading innovation and change models and how they can apply them in their practice. The second session's key focus was to help the clinicians understand individual and organisational needs and challenges and explore innovative solutions to improve the individual, team and organisational performance and apply the appropriate methods to influence people.

The programme evaluation was based on the EQ-I tool, enabling the participant to reflect and develop their emotional intelligence and 1:1 feedback, according to each need. After one month, participants attended an individual assessment and feedback session with an EQi expert and received individualised coaching on their Personal Development Plan. Six months after, participants received additional coaching and support and two reflective portfolios on critical areas for developing clinical leaders such as Leadership styles and EQi development; Innovation and Change.

All surgeons who participated in the international leadership programme during the period 2015-2019 were included: The study was conducted in two phases.

In Phase I, one of the programme researchers conducted individual in-depth face-to-face and telephonic audio-recorded interviews with sixteen thoracic surgeons. Interviews were conducted in English and lasted from 45 - 60 mins. An interview schedule using open-ended questions guided the Semi-structured interviews with the clinical professionals on reflecting on their experiences within the leadership development programme and the range of skills yet to be developed. The interviews also helped identify enablers and barriers to clinical leadership the need to employ emotional competencies in the healthcare field.

The Second Phase of the research study was focused on developing case studies as derived from two in-depth interviews with senior consultants and senior executive members of the European Society of Thoracic Surgeon. The data produced is based on their cross-national experience in different health settings. 


\section{Evaluating Key Clinical Leadership Competencies}

The focus of the interviews was on identifying critical competencies for healthcare leaders in the health care field. The table below shows the individuals responses obtained from the primary analysis. Direct quotes from participants are highlighted in each of the emotional competence's themes. These quotes were taken from the interviews to help identify some critics to justify the analysis.

From the interviews with surgeons, it was clear that clinical leaders have addressed the importance of effective communication with colleagues, patients, and families. According to all participants, communicating effectively and listening to others are considered essential competencies for the leaders as they help them evaluate situations effectively and make informed decisions leading to more significant personal and social outcomes (see Table 1).

While the importance of using effective communication means to disseminate important information, being supportive and develop healthy interpersonal relationships has already been discussed, inspiring confidence and acting as role models to others are also of crucial importance (Perez-Lopez, 2019).

In addition to the interviews data, the research project benefited from the feedback it has received from two influential senior leaders in the European Association of Thoracic surgeons with vast experience in working internationally and managing a multicultural healthcare workforce. The two European cases presented confirmed the clinicians' vital role and demonstrated that "the higher their involvement in management and governance roles is, the more productive and resource-effective their health care organisations become" (Kyriakidou et al., 2017). According to their experiences, a clinical leader may become responsible for financial resources, leading healthcare professionals, and being liable for the departmental performance.

More specifically, thoracic surgeons must have the ability to manage workplace relations and deal with ambiguous situations appropriately by inspiring calmness and confidence in others. This is in line with Stanley's (2014: 6) study which stated that "approachability, being supportive, acting as role models, helping people, inspiring confidence and having excellent communication skills are considered the primary attributes that health professionals should possess".

Similarly, helping people and being supportive are at the core of their functions as doctors. These attributes reveal the participants' ability to show empathy with the patients by taking into account their emotions and acting accordingly via a defined set of actions and regulations. While critical competencies associated with clinical leaders seem to align with most of the clinical professionals participating in this study, one of the respondents reveals that his national and organisational culture is responsible for developing reticence in his approachability to others in the professional environment. Keeping a distance, especially from patients, and retrying his emotions to protect himself was demonstrated, but his awareness of the need to express emotions appropriately and his willingness to develop this competence further confirm the presence of this essential characteristic (Perez-Lopez, 2019). 
Table 1. Surgeons examples of key clinical leadership competencies.

\begin{tabular}{|c|c|c|c|}
\hline Clinical Competencies & & Examples from professional practic & \\
\hline Self-Awareness & $\begin{array}{c}\text { An effective clinical leader should } \\
\text { demonstrate useful insights into } \\
\text { recognising self and others' } \\
\text { emotions. } \\
\text { "Through the year, I am trying to } \\
\text { manage my emotion effectively. } \\
\text { My focus is to inspire my junior } \\
\text { staff, engage and arrive at common } \\
\text { purposes within teams-“I am } \\
\text { better now in terms of how to } \\
\text { handle people." }\end{array}$ & $\begin{array}{l}\text { A competent leader is capable of } \\
\text { controlling her own and others' } \\
\text { emotions when critical } \\
\text { situations arise } \\
\text { "managing emotions are not only } \\
\text { about my welfare or the patient s... } \\
\text { I have to work on dealing with } \\
\text { other people's emotional status } \\
\text { and interests". }\end{array}$ & $\begin{array}{l}\text { Dealing with pressures in } \\
\text { emergencies, most surgeons } \\
\text { have reported that they were } \\
\text { aware of their difficulties managing } \\
\text { expectations. Using their experience } \\
\text { and good work ethics, they will } \\
\text { manage to achieve a better working } \\
\text { environment and work relationships, } \\
\text { leading to better outcomes when } \\
\text { making a decision } \\
\text { "Knowing myself and the work } \\
\text { situation has allowed me to handle } \\
\text { better relations with others." }\end{array}$ \\
\hline
\end{tabular}

Some consultants participating in the interviews revealed that they did not have any problem recognising and expressing their emotions

freely to other colleagues. However, they have admitted that before participating in the leadership development programme, they have experienced difficulty to control their anger in a difficult situation

"now I take a breath first and think for a few seconds what I am going to say to express myself more diplomatically when I provide feedback on bad practices."
A tendency to avoid emotional expressions is seen by a Senior consultant participating in this study during his interactions with patients and junior colleagues by keeping distance and maintaining a cold attitude. A recognition that is sometimes bottling up emotions negatively affects his work performance is made, and willingness to develop this skill and provide constructing feedback on someone's actions is shown throughout the conversation

"I have to, and I want to make more efforts to improve my emotional expressions."
A recognition of the necessity to control emotions is recognisable by all participants as a key competency in this profession. A participant registrar from the UK NHS acknowledged that most situations require

" The ability to stay calm and deal with my emotions later is positive for surgeons by remaining unaffected to what is happening."
Assertiveness
Female consultants participated in the interviews reported the importance not only to express themselves appropriately to others but also to listen and to understand others' point of view

"find a common way according to the medical guidelines to treat the patients by talking face to face."
Sharing opinions and analysing pros and cons through effective communication with work colleagues and patients helps surgeons to make decisions with the best outcomes for clinical leaders and patients

"I try as much as I can to say the right words to the right people at the right moment."
Communicating effectively with others is the key to discuss the pros and cons of a determined decision to be made. Also, when changes need to be implemented, good communication is crucial to make others understand and..

"...change their opinions positively and come to a balance between what we all think." 


\begin{tabular}{cc}
\hline $\begin{array}{c}\text { Efforts to maintain healthy } \\
\text { relationships at work are made } \\
\text { by organising activities in order } \\
\text { to have experiences to share away } \\
\text { from the workplace }\end{array}$ \\
$\begin{array}{c}\text { Effective communication } \\
\text { and Interpersonal } \\
\text { Relationships }\end{array}$ & $\begin{array}{c}\text { We all go to work with a different } \\
\text { perspective, positive attitude and } \\
\text { with the feeling of knowing each } \\
\text { other." }\end{array}$
\end{tabular}

A particular situation was described in which signs of empathy were shown through the difficult decisions to be made when treating Jehovah Witness patients

"I feel frustrated because my main priority is to protect people's life (...), but I need to obey to individual $s$ desire."
Most participants acknowledged the importance of working with people that have different personalities and needs. Efforts to resolve problems that might emerge leads to good relations with others, although these relations are...

“...mostly professional and only maintained in the hospital. There is no social interaction after work."
A recognition and efforts to keep good relations with other doctors and nurses are seen as essential qualities in their profession to demonstrate care for them, especially when working many hours or in busy days. Getting to know each other out of the workplace is achieved through organising special events

"Spending time with the team is something that benefits our personal and professional life."
A case description was made where the clinical leader had to make a difficult decision regarding a life-threatening operation. The risk for the patient was high, but he empathised with the family who was pushing for an operation

"I did my best to improve the last few months of his life and also to be supportive of his family."
Examples described by the participants were referred to as demonstrating empathy during constructive feedback on unprofessional practices and also when having to make a decision that was going to have a direct impact on others

"I always struggle with decisions where patients are at risk and also when I do have to select one colleague to participate in courses to develop their medical skills. I have a restricted budget, and I always found it very difficult to choose which one from my team I would send for a conference or a development course. I feel responsible that my decisions have an impact on group synergy."
Flexibility
Being resilient and flexible is seen in how an international health leader adjusts and adapts to a new healthcare system. All participants in the programme mostly highlighted those essential qualities. Even though all participants recognised the complexity of working in a very dynamic sector, they recognise their ability to be "open and flexible" to cope in a multicultural environment.
In terms of flexibility, some clinical leaders stated that coming from a different European country tested their ability to adapt to different working environments effectively and efficiently.

"Coming from a different system to the one established in the U.K.,

I have no doubt that working in the well-structured health system in this country enhanced my professional experience, helped develop important skill-set and personal competences and deal effectively with different organisational culture. Cultural and working differences only affected me when I had to work back in my home city for a couple of years".
Most participants provided useful insights into the importance of being flexible and easily adaptable to fundamental competence changes in their professions.

" There are a lot of imposed changes in the health care service all the time, and I need to follow them in order to perform at the desired NHS quality standards." 


\section{Continued}

Stress Tolerance
Recognised as one of the essential skills for the clinical leaders to possess (primarily when operating), remaining calm and composite is the key to "keep my mind thinking professionally" and also because of the consequences as "(if) I lose my temper patients could be at risk in a matter of seconds."
Dealing with stressful situations every day when at work (primarily when operating), some participants admit that staying calm and taking a breath is crucial to "give direct instructions". This, in turn, creates a positive feeling to other colleagues whose actions are reflected by how the clinical leader feels, which can

"minimise the probability of something wrong happening" by effective communication.

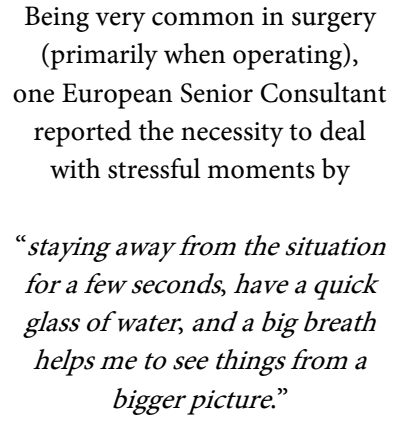

Being very common in surgery (primarily when operating), one European Senior Consultant reported the necessity to deal with stressful moments by

"staying away from the situation for a few seconds, have a quick glass of water, and a big breath helps me to see things from a bigger picture."

Trying to keep himself composite and not let these moments overwhelm him to avoid the rest of the team feel stressed.

Many similarities found between the delivery of the International Leadership Development programme for clinical leaders and the optimal process for emotional intelligence development in organisations proposed by Goleman and Cherniss (1998). The preparation phase included assessing the needs to be addressed for the specific health care context while considering individuals personal strengths and limits. Also, it encouraged participation by linking the programme content and structure to their values and needs (Perez-Lopez, 2019).

The training phase characteristics involved maximising the opportunities for practice by producing innovative solutions to improve their performance and relying on methods to help the leaders influence stakeholders, i.e. staff members, patients. Enhancing insight was also achieved in this Phase by presenting and making participants understand the use of an appropriate range of decision-making strategies in their operations as Thoracic Surgeons. The transfer and maintenance phase attained by allowing the learners to put into practice the use of the skills learned on the job, supported by reflective learning experiences, coaching and 1:1 feedback one and six months after they attended the programme and self-assessments carried out by the participants (Kyriakidou et al., 2019; Perez-Lopez, 2019).

As a final step, the framework developed by Goleman and Cherniss (1998) established the evaluation phase, which focuses on evaluating the improved performance. The last stage results explored through evaluation of the improvements in the workplace for the participants after the International Leadership Development Programme was delivered (Perez-Lopez, 2019).

Developing the desired clinical leaders' competencies requires first the identification and exercise of critical emotional intelligence qualities such as self-awareness, managing one's own and others emotions, the ability to motivate others, showing empathy and spreading positive emotions to maximise the potential of the team (Goleman, 1998). 
Reflecting on Table 2 (Kyriakidou \& Papagiannopoulos, 2018: 116-118), The search for identifying talented clinicians to lead traditionally focuses on expert knowledge, academic qualifications and outputs from their professional practice and as these are generally easier to articulate and evaluate against the selection criteria. Fundamental research studies have pointed out that the critical factors associated with performance improvement of hospitals are the following: culture, strategy, structure, excellent communication, leadership styles, physician engagement and performance, skills acquisition, training and development opportunities, effective channels of communication and dissemination of information (Brand et al., 2012). However, critical qualities such as personality traits, business ethos, personal values, essential organisational behaviour characteristics and professional manner, and motivational drivers are equally of value to identify talents. As Table 3 shows, some person specification criteria as identified in clinical leadership roles included: the determination to provide the mission and vision of professional practice and promote professionalism, ensure teamwork, enhance interprofessional collaborations with different stakeholders as well as the inclination towards lifelong learning through formal education, on the job development as well as participation in clinical leadership development programmes.

Table 2. Talent management: Developing leadership, not leaders.

Talented leaders/managers are a sine qua non of every Health Care System.

Several years ago I had the opportunity to witness the Belgian Health Care System employed as a starting Consultant. Soon after commencement of employment I realized that the Department had all skills and expertise required to provide an excellent care to patients but was not able to identify well established, standardized and recorded standard operating procedures (SOP) for the postoperative management of patients. A common language amongst nursing, junior medical and senior medical staff members.

Obstacles to overcome:

1) Persuade team members of the need of such SOP in an established practice

2) Engage senior team members with established ideas and habits

3) Engage all 3 core teams of the Department (nursing staff, junior doctors, senior medical staff)

The need was obvious but the message was challenging. Being a fresh member and not the most senior I spent a period of time preparing an appropriate business case tailored to the needs of the individual system based on evidence (preparation and tailor made presentation).

I therefore identified and approached individual talents within all 3 teams who were respected amongst peers, were influential but also had the skills and the vision to identify innovation (identify talents).

I offered a period of consultation, allowing the case to become embedded, listening and not just hearing comments and suggestions (team work, sense of ownership, opportunity to be heard).

The most critical step was assignment of segments of the business case to individuals from all different teams with short cycles of auditing and insisting on deadlines (team work, healthy competition amongst team members, global engagement and ownership, team building, delegate responsibilities while coaching and keeping control, identify and employ different styles of leadership).

At the conclusion of the business case and the successful implementation of SOP an official presentation was arranged in Hospital. It allowed other teams to witness a good piece of work, offered a well-perceived recognition to all who worked hard for the completion, teased out the talents within the team and awarded the enthusiasts and innovators of the team. The end result was rewarding as the business case was completed in time, was accepted by all team members as it had several individual flavors, and left a sense of satisfaction and pride to all those who had worked with passion and enthusiasm (sense of ownership, address and reward the talents, share good ideas and market them to a wider audience, keep talents engaged). 
Table 3. Critical Competencies for Clinical Leadership.

An example of participative clinical leadership was the start a single port minimally invasive thoracic surgery program in the Department of Thoracic Surgery in Ancona, Italy, in which I have been working for more than 20 years. In the early 2000s, the advent of minimally invasive thoracic surgery, keyhole surgery revolutionized our specialty. Our centre was experiencing a difficult period of reduced productivity.

There was a need of an effective change that could boost the image of the unit and attract referrals.

In that period I had the chance to observe this new technique from a famous surgeon. I immediately perceived this technique as a valuable change to introduce in our unit. A change that could: 1 . Revitalize the morale and enthusiasm of the team and 2. Increase surgical referrals and productivity.

The most important leadership skill to successfully implement this technique in our unit was my ability to set direction and communicate this to my colleagues. In that situation, it was critical to convince the team about the strategic importance of implementing the new technique. Communication was the key to the success of the program. In fact, the first step was to communicate my vision to the other team members and buy them in. I presented and discussed my vision and objectives with my colleagues in the context of the emerging needs of the unit. Using a participative leadership style I encouraged my colleagues to share their ideas and opinions engaging them in the process. This was important as they all felt part of the project even if they initially were not directly involved in the surgery. The stepwise approach was well defined since the start in order to avoid misunderstanding and win resistance. Taking into consideration the opinions of my team members, I was able to set direction by building a guiding team consisting of two surgeons, who started to learn and apply this technique and subsequently were able to tutor the rest of the team. This lead to increased surgical activity and productivity of the unit again.

Clinical leaders should lead with purpose and precise outcomes. They are emotionally intelligent individuals who are led by their value code and ethos, excellent interpersonal relationships with the people around them, empowering teamworking, democratic and participating leadership and inspiring others to make a difference through transformation and innovation in the professional practice.

The clinical leaders participating in the study (Kyriakidou \& Papagiannopoulos, 2018: 116-118) also outlined a wide range of emotional competencies that are in line with the ones identified in the theoretical skills framework for health professionals, suggested by Warren (2013). Some key competencies that have been addressed are the following:

- A wareness that helps them to comprehend situations and focus on them appropriately by collaborating and working in teams to succeed;

- The regulation concerning the ability to moderate emotions, which is fundamental to solving problems and maintaining healthy and professional relationships with others;

- The compassion that demonstrated through connections and interactions with patients enables them to understand the emotional states of others;

- Emotional intelligence itself, which led them to interact from a social perspective through the ability to evaluate and understand how patients and co-workers react to a determined situation and act upon it accordingly (Kyriakidou et al., 2019; Perez-Lopez, 2019). 


\section{Concluding Remarks}

Increasing complexity in healthcare requires European Health Management Systems to develop clinical leaders who can identify both personal and clinical needs and deal with current challenges in their practice. They have to be able to shift and adapt quickly, are innovative, resourceful and competent, thrive on organisational change, inspire others and cope effectively with the uncertainty and resistance to change (for example, causes such as Brexit, pandemic situations such as COVID-19) for those they lead (Dolton et al., 2018; Veronesi et al., 2018; Kyriakidou et al., 2017; Kyriakidou \& Papagiannopoulos, 2018; Enock and Markwell, 2010). Strong leadership is the critical driver of overall organisational performance, and well-constructed talent management systems remain critical to developing and retaining a thriving pool of influential healthcare leaders capable of meeting growing demands for high quality, cost-effective care.

Moreover, innovative Human Resource practices may lead to a tremendous organisational cultural shift within main stakeholders involved in managing healthcare organisations, allowing and promoting new quality measures and patients-centred services and processes development. Also, they could assist in shaping learning and development opportunities and involvement of clinicians, healthcare professionals and other key stakeholders such as Clinical Commissioners in key managerial roles and responsibilities. In such a way, clinical leaders would be capable of exercising leadership and Emotional Intelligence, identifying talent within their hospital, and making informed decisions (Kyriakidou \& Papagiannopoulos, 2018).

The two European Cases presented in this paper also demonstrated the importance of the leaders' ability to set Direction, promote good practice and quality and safe services, and communicate effectively with health professionals at all levels. Effective clinical leadership and development are considered paramount in maintaining patients-centre services and promoting quality in the health sector (Veronesi et al., 2013; Montoute, 2013; Dorgan et al., 2010).

While the possession of appropriate professional expertise as well as the identification of critical competencies are considered as essential criteria for screening and assessing a health professional' creditability for a particular role/position/ responsibilities, personality traits and personal drivers also account for assessing a clinical professional's potential for developing leadership qualities, hence promotional opportunities into senior leadership positions (Kyriakidou \& Papagiannopoulos, 2018).

\section{Limitation and Further Research}

Edmonstone (2014) argues that the focus on competency-based leader development has limited effect on effective clinical leadership in the U.K., despite its potential usefulness, as evidenced in this study. Although a considerable discussion has occurred on the need for clinical leadership competencies development, extensive evaluation of leader development programmes and large-scale evi- 
dence is needed in a further follow up study. Our paper discusses the added value of reflective case studies and the use of a control group in evaluating the effectiveness of a leadership programme in their professional practice and development. However, the relatively small sample size limited the extent and depth of multivariate analysis that could be performed. The empirical study demonstrated the impact such programmes have on doctors' medical practice, especially engaging and within their health organizations. The paper provides an example of a framework of skills needed for clinical leadership development and a methodological way to evaluate clinical professionals' leadership development programmes.

Further empirical work is essential to explore the relationships between targeted training and professional development interventions. However, intervening at the level of the individual may not be enough. Future research should focus on the System-wide interventions and how those interventions impact clinical leaders' engagement in management and leadership practices through the different stage of the professional career.

\section{Acknowledgements}

This study has been done within the Postgraduate Health and Social Care Management Programme framework of the University of West Attica in collaboration with the Leeds Beckett University, UK.

\section{Conflicts of Interest}

The authors declare no conflicts of interest regarding the publication of this paper.

\section{References}

Auerbach, D. I, Staiger, D. O., \& Buerhaus, P. I (2018). Growing Ranks of Advanced Practice Clinicians-Implications for the Physician Workforce. The New England Journal of Medicine, 378, 2358-2360. https://doi.org/10.1056/NEJMp1801869

Brand, C. A., Baker, A. L., Morello, R. T., Vitale, M. R., Evans, S.M., Scott, I. A., Stolewinder, J. U., \& Cameron, P. A. (2012). A Review of Hospital Characteristics Associated with Improved. International Journal for Quality in Health Care, 24, 483-494. https://doi.org/10.1093/intqhc/mzs044

Cherniss, C., \& Goleman, D. (2001). The Emotionally Intelligent Workplace. How to Select for, Measure, and Improve Emotional Intelligence in Individuals, Groups, and Organisations (pp. 3-10). San Francisco, CA: John Wiley \& Sons.

Cherniss, C., Goleman, D., Emmerling, R., Cowan, K., \& Adler, M. (1998). Bringing Emotional Intelligence to the Workplace. A Technical Report Issued by the Consortium for Research on Emotional Intelligence in Organisations. http://www.eiconsortium.org/reports/technical_report.html

Cherry, M. G., Fletcher, I., O’Sullivan, H., \& Dornan, T. (2014). Emotional Intelligence in Medical Education: A Critical Review. Medical Education, 48, 468-478.

https://doi.org/10.1111/medu.12406

Clay-Williams, R., Nosrati, H., Cunningham, F. C., Hillman, K., \& Braithwaite, J. (2014). 
Do Large-Scale Hospital- and System-Wide Interventions Improve Patient Outcomes: A Systematic Review. BMC Health Services Research, 4, Article No. 369. https://doi.org/10.1186/1472-6963-14-369

Crocker, J. C., Ricci-Cabello, I., Parker, A., Hirst, J. A., Chant, A., Petit-Zeman, S. et al. (2018). Impact of Patient and Public Involvement on Enrolment and Retention in Clinical Trials: Systematic Review and Meta-Analysis. BMJ, 363, k4738.

https://doi.org/10.1136/bmj.k4738

Daly, J., Jackson, D., Mannix, J., Davidson, P. M., \& Hutchinson, M. (2014). The Importance of Clinical Leadership in the Hospital Setting. Journal Health Leaders, 6, 75-83. https://doi.org/10.2147/JHL.S46161

Dolton, P., Nguyen, D., Castellanos, M., \& Rolfe, H. (2018). Brexit and the Health and Social Care Workforce in the UK. London: National Institute of Economic and Social Research.

http://www.niesr.ac.uk/publications/Brexit-and-health-social-care-workforce-UK

Dorgan, S. et al. (2010). Management in Healthcare: Why Good Practice Really Matters, Joint with McKinsey \& Co and Centre for Economic Performance at the London School of Economics. Technical Report.

Edmonstone, J. D. (2014). Whither the Elephant? The Continuing Development of Clinical Leadership in the UK National Health Service. International Journal of Health Planning and Management, 29, 280-291. https://doi.org/10.1002/hpm.2245

Enock, K., \& Markwell, S. (2010). Interactions between Managers, Doctors and Others. https://www.healthknowledge.org.uk/public-health-textbook/organisation-managemen $\mathrm{t} / 5 \mathrm{a}$-understanding-itd/interactions

Francis, R. (2013). Report of the Mid Staffordshire NHS Trust Public Inquiry-Executive Summary. London: The Stationery Office.

http://www.midstaffspublicinquiry.com/sites/default/files/report/Executive\%20summa ry.pdf

Gardiner, H. (1983). Frames of Mind: The Theory of Multiple Intelligences. New York, NY: Basic Books.

Gauld, R. (2017). The Theory and Practice of Integrative Health Care Governance: The Case of New Zealand's Alliances. Journal of Integrated Care, 25, 61-72. https://doi.org/10.1108/JICA-10-2016-0035

Goleman, D. (1998). Working with Emotional Intelligence. London: Bloomsbury Publishing.

Goleman, D. (2000). Emotional Intelligence: Leadership That Gets Results. Harvard Business Review. https://hbr.org/2000/03/leadership-that-gets-results

Goleman, D., \& Cherniss, C. (1998). The Emotionally Intelligent Workplace: How to Select for, Measure, and Improve Emotional Intelligence in Individuals, Groups, and Organizations. San Francisco, CA: Jossey-Bass.

Groves, K., McEnrue, M., \& Shen, W. (2008). Developing and Measuring the Emotional Intelligence of Leaders. Journal of Management Development, 27, 225-250.

https://doi.org/10.1108/02621710810849353

Ham, C., \& Dickinson, H. (2008). Engaging Doctors in Leadership. What We Can Learn from International Experience and Research Evidence. Birmingham: Health Services Management Centre, University of Birmingham.

Hamilton, P., Spurgeon, P., Clark, J., Dent, J., \& Armit, K. (2008). Engaging Doctors: Can Doctors Influence Organisational Performance? Coventry: NHS Institute for Innovation and Improvement.

https://www.fmlm.ac.uk/resources/engaging-doctors-can-doctors-influence-organisati 
onal-performance

Hodzic, S., Scharfen, J., Ripoll, P., Holling, H., \& Zenasni, F. (2018). How Efficient Are Emotional Intelligence Training: A Meta-Analysis. Emotion Review, 10, 138-148. https://doi.org/10.1177/1754073917708613

Jayaraman, S., Parvaiz Talib, P., \& Ahmad, F. (2018). Integrated Talent Management Scale Construction and Initial Validation. Sage Open, 8, 1-12. https://doi.org/10.1177/2158244018780965

Kafetsios, K., \& Zampetakis, L. A. (2008). Emotional Intelligence and Job Satisfaction: Testing the Mediatory Role of Positive and Negative Affect at Work. Personality and Individual Differences, 44, 710-720. https://doi.org/10.1016/j.paid.2007.10.004

Kirkpatrick, I. H., Kuhlmann, K., Veronesi, G. and Gianluca, E. (2016). Clinical Management and Professionalism. In E. Kuhlmann, R. H. Blank, I. L. Bourgeault, \& C. Wendt (Eds.), The Palgrave International Handbook of Healthcare Policy and Governance (pp. 325-340). London: Palgrave Macmillan. https://doi.org/10.1057/9781137384935_20

Kyriakidou, N., \& Papagiannopoulos, K. (2018). Clinical Leadership in the European Health Sector. In P. Turner (Ed.), Leadership in Healthcare: Delivering Organisational Transformation and Operational Excellence (pp. 116-118). London: Palgrave MacMillan.

Kyriakidou, N., Papagiannopoulos, K., \& Bocceli, A. (2017). Developing Talent in Clinical Leadership. In P. Turner (Ed.), Talent Management in Healthcare: Exploring How the World's Health Service Organisations Attract, Manage and Develop Talent (pp. 241-243). London: Palgrave MacMillan.

Kyriakidou, N., Papagiannopoulos, K., Pierrakos, G., Turner, P., \& Beech, N. (2019). Exploring the Need for Clinical Leadership Development. A Cross National Study. 12th Euromed Conference: Business Management Theories and Practices in a Dynamic Competitive Environment, Thessaloniki, 18-20 September 2019, 547-558.

MacPhee, M., Chang, L, Lee, D., \& Spiri, W. (2013). Global Health Care Leadership Development: Trends to Consider. Journal Healthcare Leadership, 5, 21-29. https://doi.org/10.2147/JHL.S23010

Mayer, J. D., Salovey, P., \& Caruso, D. R. (2002). Mayer-Salovey-Caruso Emotional Intelligence Test (MSCEIT) Item Booklet. UNH Personality Lab No. 26, Durham, NH: University of New Hampshire Personality Lab.

https://scholars.unh.edu/personality_lab/26

Montoute, K. (2013). Clinical Directors: Learning to Swim at the Deep End. Health Services Journal, 28, 26-27.

Mountford, J., \& Webb, C. (2009). When Clinicians Lead. McKinsey Quarterly.

Nelis, D., Quoidbach, J., Mikolajczak, M., \& Hansenne, M. (2009). Increasing Emotional Intelligence: (How) Is It Possible? Personality and Individual Differences, 47, 36-41. https://doi.org/10.1016/j.paid.2009.01.046

NHS Institute for Innovation and Improvement and Academy of Medical Royal Colleges (2010). Medical Leadership Competency Framework (3rd ed.). Coventry: NHS Institute for Innovation and Improvement. http://cs1.e-learningforhealthcare.org.uk/public/CLE/CLE_01_002/Clinical_Leadership _Competency_Framework.pdf

Payne, W. L. (1985). A Study of Emotion: Developing Emotional Intelligence; Self-Integration; Relating to Fear, Pain and Desire. Doctoral Dissertation, Cincinnati, OH: The Union Institute.

Perez-Lopez, M. C. (2019). Exploring the Impact of Emotional Intelligence (E.I.) on 
Health Leadership Development Programs. Postgraduate Dissertation, Leeds: Leeds Beckett University.

Pierrakos, G., Goula, A., Latsou, D., Platis, C., Sarris, M., \& Soulis, S. (2017). Opinion of Citizens in Primary Health Care Management and Offered Services by Local Authorities. International Journal of Strategic Innovative Marketing, 4, 47-63.

Pierrakos, G., Sarris, M., Amitsis, G., Kyriopoulos, J., \& Soulis, S. (2006). Training Needs and Vocational Training of Human Resource in Health. Nosileftiki, 45, 543-551.

Pierrakos, G., Tzamalouka, G., Latsou, D., Goula, A., Asonitou, S., Adamakidou, T., Tzamaloukas, D., Pateras, J., Platis, C., \& Kalokerinou, A. (2016). Health Professionals' Continuing Training Needs for Improving Home Care Services. International Journal of Strategic Innovative Marketing, 2, 46-59.

Reichenpfader, U., Carlfjord, S., \& Nilsen, P. (2015). Leadership in Evidence-Based Practice: A Systematic Review. Leadership in Health Services, 28. https://doi.org/10.1108/LHS-08-2014-0061

Royal College of Physicians (2005). Doctors in Society: Medical Professionalism in a Changing World. London: Royal College of Physicians.

Salovey, P., \& Mayer, J. (1990). Emotional Intelligence. Imagination, Cognition, and Personality, 9, 185-211. https://doi.org/10.2190/DUGG-P24E-52WK-6CDG

Stanley, D. (2014). Clinical Leadership Characteristics Confirmed. Journal of Research in Nursing, 19, 118-128. https://doi.org/10.1177/1744987112464630

The King's Fund (2011). The Future of Leadership and Management at NHS. London: The King's Fund

The King's Fund (2012). Leadership and Engagement for Improvement in the NHS. London: The King's Fund.

Turner, P. (2020). Leadership in Healthcare. London: Palgrave MacMillan.

Veronesi, G., Kirkpatrick, I., \& Vallascas, F. (2013). Clinicians on Board: What Difference Does It Make? Social Science \& Medicine, 77, 147-155.

https://doi.org/10.1016/j.socscimed.2012.11.019

Veronesi, G., Kirkpatrick, I., Sturdy, A., Oliver-Blanco, A., \& Reguera, N. (2018). The Impact of Management Consultants on Public Service Efficiency. Policy \& Politics, 47, 77-96. https://doi.org/10.1332/030557318X15167881150799

Warren, B. (2013). Healthcare Emotional Intelligence: Its Role in Patient Outcomes and Organisational Success.

https://www.beckershospitalreview.com/hospital-management-administration/healthc are-emotional-intelligence-its-role-in-patient-outcomes-and-organizational-success.ht $\underline{\mathrm{ml}}$

Weng, H. C. (2008). Does the Physician's Emotional Intelligence Matter? Impacts of the Physician's Emotional Intelligence on the Trust, Patient-Physician Relationship, and Satisfaction. Health Care Management Review, 33, 280-288. https://doi.org/10.1097/01.HCM.0000318765.52148.b3

West, M. A., Eckert, R., Steward, K., \& Pasmore, B. (2014). Developing Collective Leadership for Healthcare. London: The King's Fund.

https://doi.org/10.35613/ccl.2014.1013 